DOI: 10.20472/IAC.2017.030.018

\title{
HYUN-KYU KANG
}

Korea Institute of Sicence \& Technology Evaluation and Planning, Korea, Republic of

\section{POLICY ANALYSIS IN EX-ANTE EVALUATION OF GOVERNMENT R\&D PROGRAMS}

\begin{abstract}
:
In order to enhance the efficiency of government investment on research and development (R\&D), since 2008 the Korean government has applied the preliminary feasibility study (PFS) to new large scale government $R \& D$ programs. The PFS of $R \& D$ programs is an ex-ante evaluation that is performed in point of views of technology, policy and economy.

Because a lot of tax should be expended to conduct a government $R \& D$ program, the program should be conducted based on the national science and technology (S\&T) strategies, and the program expense should be used meaningly on the basis of the consensus of national policy and society. Also it is good that all risk factors should be known before starting the R\&D program. Therefore the feasibility analysis on policy is very important part of the ex-ante evaluation of R\&D program. In this paper, main contents of the feasibility analysis on policy will be explained. The policy analysis is composed of the evaluation criteria of three layers and deals with policy issues and other issues that could not be analyzed in technological analysis and economic analysis.
\end{abstract}

\section{Keywords:}

Preliminary feasibility study, Ex-ante evaluation, Government R\&D program, Policy analysis

JEL Classification: 032, 038, D81 


\section{Introduction}

The Korea government has increased the research and development (R\&D) budget over two times during 10 years from about $\$ 8.1$ billion in 2006 to about $\$ 17.4$ billion in 2016 . From the middle of 2000, the Korean government began to take an interest in raising the efficiency of government R\&D investment as well as the quantitative increase of R\&D expenditure.

Since 2008, as a part of measures for enhancing the efficiency of the fiscal management, the Korean government introduced the Preliminary Feasibility Study (PFS) to newly proposed large-scaled, long-term $R \& D$ programs, of which total budget exceeding about $\$ 50$ million including about $\$ 30$ million or more in the government expenditure. The National Finance Act of 2006 provides the legal basis of PFS (Ahn, 2017).

The PFS have been performed to predict the potential results of planned R\&D programs and to raise the effectiveness of government R\&D investments by selecting R\&D programs that has high viability. In addition, the FPS could contribute to allocate more funds to better R\&D programs by cutting poorly planned R\&D program. Only the programs which get the credit for the feasibility through the PFS could acquire a qualification of a budget investment (Yim and Kang, 2011).

The fundamental purpose of the PFS is to provide important information to help the Ministry of Strategy and Finance decide whether to expend funds to R\&D programs proposed by government ministries. The Ministry of Strategy and Finance (MoSF), fiscal authority, can make an informed decision based on results of the PFS on each program proposal. In addition, the PFS is contributing the improvement of an R\&D program proposal by complementing its small drawbacks during the PFS process (Kang, 2012). Korea Institute of Science \& Technology Evaluation and Planning (KISTEP) is main agency performing the PFS of R\&D program. Since 2008, KISTEP has conducted the PFS of 140 government R\&D programs.

It is difficult to evaluate the uncertain performance of any R\&D program in the future. In order to establish the credible ex-ante evaluation system, 'the standard guideline for PFS of $R \& D$ programs' was published. The standard guideline is an official document which evaluation approaches and methods are systematized. KISTEP published the 2nd edition of standard guideline of PFS for R\&D program in 2014 (KISTEP, 2014; Kang, 2015).

In the PFS, 3 major criteria are applied to measure comprehensively effects of the R\&D program in aspects of technology, policy, and economy as shown in Figure 1. Technological analysis, policy analysis and economic analysis are performed independently and results of these analyses are combined to deliver the final result. AHP (Analytic Hierarchy Process) (Saaty et al., 2006) method has been utilized as a means of collecting the decision-making information for examined R\&D programs in the PFS. 
Figure 1: Main criteria of the PFS on R\&D program

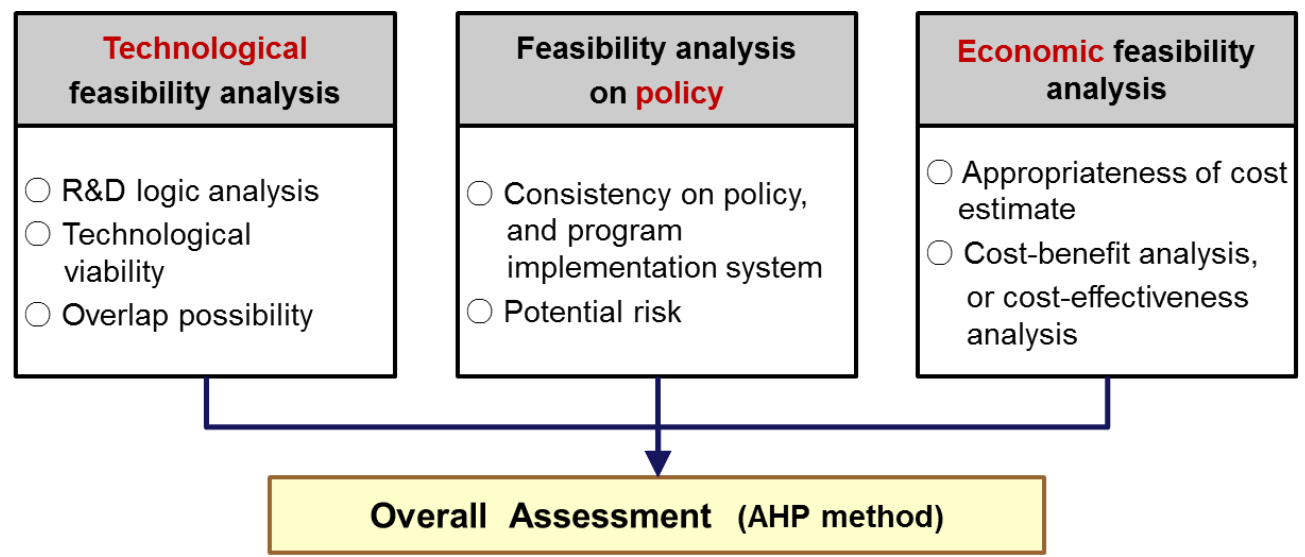

In order to conduct the government R\&D program, a lot of tax should be expended. Therefore government R\&D program should be conducted based on the national science and technology (S\&T) strategies, and the program expense should be used meaningly in accordance with the consensus of policy and society. Therefore the evaluation related to policy issues is an important part in the PFS on R\&D program and we have devised approaches to analyze the feasibility on policy. In this paper, main contents of the feasibility analysis on policy will be explained.

\section{Feasibility analysis on policy}

Figure 2 shows the basic analysis structure of the PFS on R\&D program.

Figure 2: Basic analysis structure of the PFS on R\&D programs

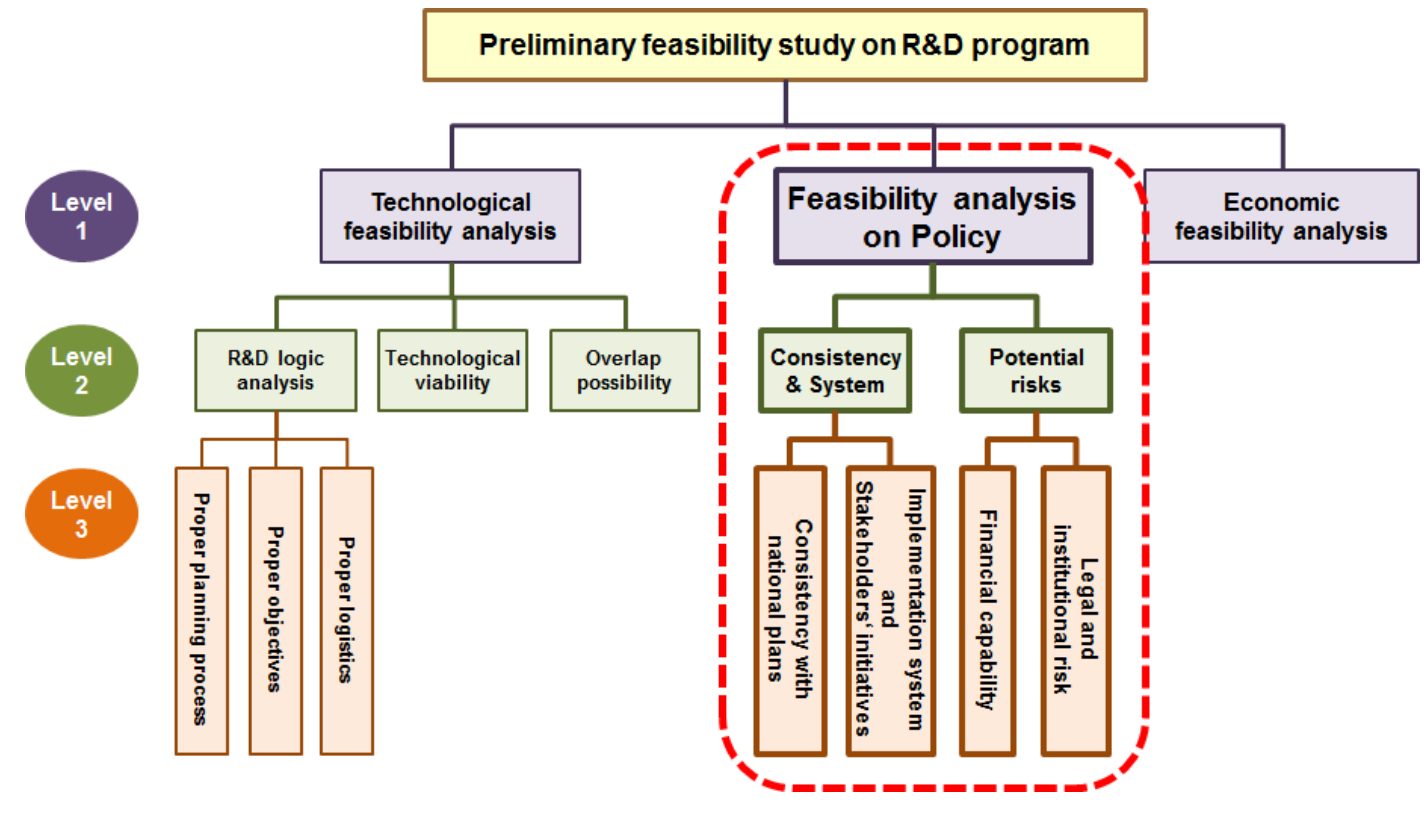


The feasibility analysis on policy deals with policy issues and other issues that could not be analyzed in technological feasibility analysis and economic feasibility analysis. This evaluation criterion has two second level sub-criteria, such as 'consistency on policy, and program implementation system' and 'potential risk'.

\section{Figure 3: Analysis structure of feasibility analysis on policy}

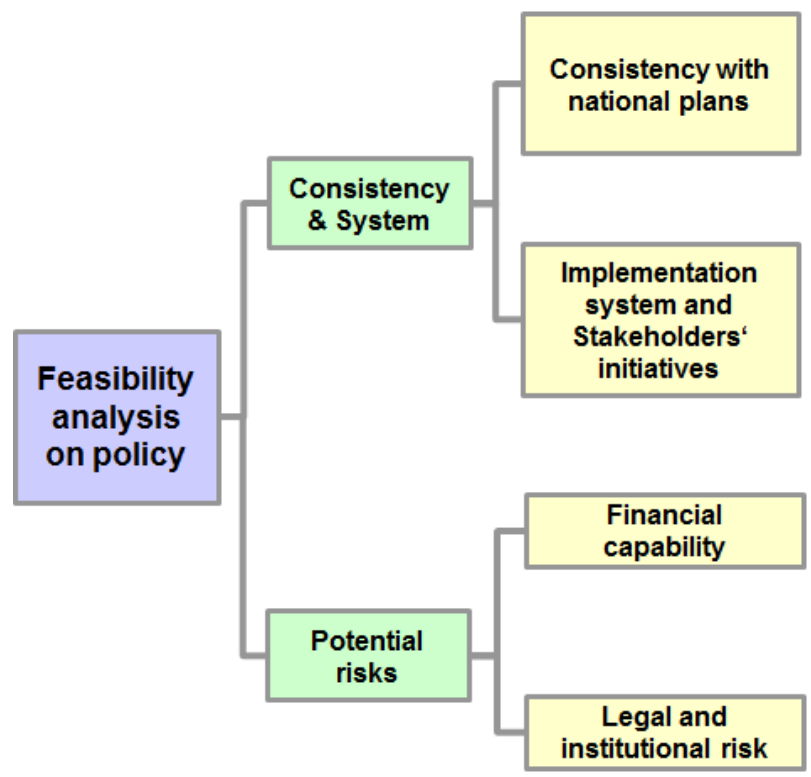

Analyze the position of the R\&D program in the whole governmental S\&T policy by investigating related national $R \& D$ strategies

Analyze the governance in the R\&D program and the initiative of stakeholders to understand the viability of successful operation of program

Identify the potential issues on the funding of both government and private sectors for the R\&D program

Investigate the potential issues related the violation of domestic laws or international trade law during implementing the program or deploying its results

\section{A. Consistency on policy, and program implementation system}

This second level criterion has two third level criteria, such as 'consistency with national plans' and 'implementation system and stakeholders' initiatives.'

In the criterion of 'consistency with national plans', it is analyzed the position of the R\&D program in the whole governmental science and technology policy by investigating related national $R \& D$ strategies.

In the criterion of 'implementation system and stakeholders' initiatives', the governance in the R\&D program and the initiatives of stakeholders are analyzed to understand the viability of successful operation of the program.

\section{B. Potential risk}

This second level criterion has two third level criteria, such as 'financial capability' and 'legal and institutional risk.' 
In the criterion of the financial capability, it is identified potential issues on the fund investment of both government and private sectors for the R\&D program.

In the criterion of the legal and institutional risk, it is investigated potential issues related to the violation of domestic laws or international trade law during implementing the program or deploying its results.

In following parts, sub-criteria will be explained in detail.

\section{Consistency \& initiative}

\section{A. Consistency with national plans}

'The consistency with national plans' is a criterion to assess whether the R\&D program will be promoted with consistency based on national policies, for realizing the national S\&T strategies. For assessing by this criterion, the goals and objectives of the R\&D program could be compared and analyzed with contents of national S\&T plans. In Korea, National S\&T strategy has been organized in a hierarchical structure that 'the Science and Technology Basic Plan', which is a top-level plan, leads a lot of sub S\&T plans of various technological and policy areas.

For the sake of efficient use of limited governmental R\&D funding, the government specifies the technology to invest through the selection and concentration in the mediumand long-term S\&T plans For example: 120 national science \& technology in 3rd Science and Technology Basic Plan

For $R \& D$ program to develop a specific technology or to construct a specific $R \& D$ infrastructure, we can determine that the program has a consistency with national S\&T strategy, if the technology or the R\&D infrastructure is described obviously in any S\&T plan. The Science and Technology Basic Plan, which is top-level plan, is analyzed compulsorily, and other S\&T plans related to the R\&D program are analyzed selectively. The consistency level between the R\&D program and any S\&T plan is evaluated in 3 level, such as high, middle, low.

\section{B. Implementation system and stakeholders' initiatives}

Implementation systems of government R\&D program are diverse, and the implementation system to accordance with the characteristics of the individual R\&D program is likely to affect the success or failure of the program. For the successful enforcement of R\&D program, the role-sharing and cooperation system among principal ministry, related ministries and research institutes, should be reviewed in ex-ante 
evaluation. Also the efficient program operation scheme and the strong will of participating agents must be considered importantly.

In the point of view of R\&D program governance, it is needed to analyze the propriety of comprehensive program management system which involves the vertical funds transfer system and horizontal cooperation system. In other words, the evaluation of the implementation system is to consider the appropriateness of program management systems and procedures to achieve the policy goals from point of legal · institutional view, and to analyze the efficiency of program operations scheme.

In order to evaluate the stakeholders' initiative, the will of agents to conduct the R\&D program and the extent of the preference of the stakeholders (beneficiaries or expense person) could be analyzed. The will to conduct can be evaluated by investigating the extent of preparation of detailed contents and strategy for the R\&D program proposed by a ministry. The extent of the preference of the stakeholders can be evaluated by investigating the number of agents to try to participate, such as research institutes, companies, universities, the extent of their will to participate, and the size of matching funds of private capital, etc.

\section{Potential Risks}

Risk factor analysis is performed to enhance the understanding of the stakeholders' responsibility by increasing the transparency of risk information of the $R \& D$ program. The potential risk analysis in the feasibility analysis on policy is to investigate external risk factors not directly relevant to the technology development activities, such as fund procurement risk and legal \& institutional risk.

\section{A. Financial Capability}

The financial capability is to analyze the possibility of problems in terms of time and scale of the R\&D program expense. By doing this, it is able to consider the risk factors of delay of $R \& D$ program due to the problem of financial procurement. The R\&D program expense is classified as central government expenditure, local government expenditure, matching fund of private capital. Concreteness and risk factors of the procurement plan by these financial resources are analyzed to evaluate the financial risk.

\section{B. Legal and institutional risk}

Legal and institutional risk factor is classified as the domestic laws and institutions and international treaties and conventions. Because government R\&D program is conducted by a public investment, it should be analyzed whether it would be carried out in 
accordance with the relevant laws, institutions and provisions. In addition, even in R\&D activities and the use and spread of outcomes from the R\&D program, it is possible to find a case of conflict with the law.

There is a point that should be considered, when the product obtained through the R\&D program would be applied as international trade goods. As the international trade is active, incidents related to government R\&D programs have increased cases that evoke the conflict in relation to the foreign nations. Because R\&D activities are considered to be spread into the industry in conjunction with technological innovation, the possibility that $R \& D$ activities cause trade issues by regulations among nations, is higher than in the past. In this connection, for $R \& D$ programs that would develop industrial technologies, Agreement on Subsidies and Countervailing Measures established by World Trade Organization (WTO) should be considered.

Objective information on these risk factors could be utilized as an important basic data for the risk response plan in the implementation process of the R\&D program, so there is a need for careful consideration about risk factors at the stage planning of program.

\section{Conclusions}

The government $R \& D$ program should be begun on the basis of the consensus of national policy and society. Also it is good that all risk factors should be known before starting the R\&D program. Therefore the feasibility analysis on policy is very important part of the ex-ante evaluation of R\&D program.

The preliminary feasibility study, which is an ex-ante evaluation on $R \& D$ program, is one of the important budgetary processes in Korea. Because the ex-ante evaluation is applied to an R\&D program proposal just written on papers, it is not easy to evaluate at present the uncertain performance in the future. Thus further studies of analysis methodology should be conducted steadily for the more credible ex-ante evaluation of R\&D programs.

\section{References}

Ahn, S.J. (2017), Institutional basis for research boom: From catch-up development to advanced economy, Technological Forecasting and Social Change, In press.

KANG, H.K. (2012), Improvement of New Government R\&D Program Plans through Preliminary Feasibility Studies, International Journal of Social, Behavioral, Educational, Economic, Business and Industrial Engineering, 6(11): 2963 2965.

KANG, H.K. (2015), Development of guideline for preliminary feasibility study on government R\&D programs in Korea, Proceedings of 19th International Academic Conference, IISES, Florence, Italy, September 2015, 387 395

Korea Institute of Science \& Technology Evaluation and Planning (KISTEP) (2014), Standard guideline for preliminary feasibility study on R\&D programs (2nd Edition), November 2014 (in Korean). 
SAATY, T.L. and VARGAS, L.G. (2006), Decision Making with the Analytic Networking Process; Economic, Political, Social and Technological Applications with Benefits, Opportunities, Costs and Risks, Springer.

YIM, S. and KANG, H.K. (2011), Feasibility Analysis Studies on New National R\&D Programs in Korea, International Journal of Social, Behavioral, Educational, Economic, Business and Industrial Engineering, 5(11): 1657 1659 